\title{
Push enteroscopy in management of suspected small bowel diseases: Is it still needed?
}

\author{
Mohamed A. Tawfik, Abd Allah El-Sawy \\ Department of Internal Medicine, Gastroenterology and Hepatology Unit, Tanta University, Tanta, Egypt
}

\begin{abstract}
Background and Study Aims: Small intestinal lesions still represent a challenge in diagnosis and treatment. The detection of small bowel lesions has been difficult due to limited visualization of the small bowel by esophagogastroduodenoscopy (EGD) and colonoscopy. In this study, we aimed to assess the efficacy of push enteroscopy (PE) in diagnosis and therapy of small bowel lesions in different indications in a single gastrointestinal (GI) endoscopy center. Patients and Methods: In the period from January 2012 to December 2013, 14 patients presented with different indications referred to the Tanta Endoscopy Center, a division of the internal medicine department and one of the most important centers in Delta Nile in Egypt. Patients were referred due to different indications, and they underwent examination by PE. Results: The overall diagnostic yield for patients with suspected small bowel disease was $57 \%$ and for patients with both occult and overt obscure bleeding $63 \%$. Ectopic jejunal varices was the most common diagnosis in patients with GI blood loss. Patients with active overt GI bleeding had a higher diagnostic yield. The procedure was tolerated well, and no complications occurred. Conclusions: Additional endoscopic evaluation of the proximal small bowel by PE should be considered in all patients with nonspecific findings on EGD and colonoscopy especially with occult or overt bleeding, balloon-assisted enteroscopy may be not readily available and capsule endoscopy is expensive.

Key words Angiodysplasia, gastrointestinal hemorrhage, push enteroscopy, small bowel disease
\end{abstract}

\section{Introduction}

The field of endoscopy has revolutionized the diagnosis and treatment of gastrointestinal (GI) diseases in recent years. However, imaging of the small bowel is still limited. Small bowel barium follow-through is the most commonly used investigation tool but has a low sensitivity and a specificity of only $10 \%$ for detecting pathology. ${ }^{[1]}$

Thus, the quest for inspection and biopsy of a small intestine has been pursued enthusiastically for many

\begin{tabular}{|l|c|}
\hline \multicolumn{2}{|c|}{ Access this article online } \\
\hline \multirow{2}{*}{$\begin{array}{l}\text { Website: } \\
\text { www.jdeonline.in }\end{array}$} & Quick Response Code \\
\hline DOI: & \\
10.4103/0976-5042.147498 & \\
\hline
\end{tabular}

years. ${ }^{[2]}$ The detection of small bowel lesions has been difficult due to limited visualization of the small bowel by esophagogastroduodenoscopy (EGD) and colonoscopy. ${ }^{[3]}$

Small bowel is the most difficult part of the GI tract to image due to its location, length, and tortuosity. ${ }^{[4]}$ Push enteroscopy (PE), which is endoscopy of the small bowel, has been for investigation of small bowel diseases in which $\mathrm{PE}$ is actively advanced under vision into the small bowel. The advantages of this method are that the biopsy and endoscopic treatment of mucosal lesions can be performed. ${ }^{[2]}$

The most important clinical indication for visualization of the small intestine is obscure GI bleeding or iron-deficiency anemia (IDA), when the source of blood loss cannot be found in the EGD or colonoscopy. It is now recognized that small intestinal lesions account for a significant proportion of patients with obscure GI bleeding and IDA. ${ }^{[5]}$ In $20 \%$ of patients with IDA, a routine upper and lower GI endoscopy may not ascertain GI cause during hospital admission. ${ }^{[6]}$ 
Many studies have concluded that on evaluation of GI tract for IDA; most of the lesions were in lower GI tract and have recommended that evaluation for IDA should be started with lower GI examination. ${ }^{[7-9]}$

Small - bowel bleedings with an origin located between the papilla and the ileocecal valve are defined as mid GI bleeding. The diagnostic yield of $\mathrm{PE}$ was reported to be in the range of $20-80 \%{ }^{[10]}$

Push enteroscopy can be considered as the first diagnostic step in patients with suspected small bowel stenosis because capsule endoscopy (CE) should be avoided in these cases due to the risk of capsule retention. ${ }^{[11]}$

The present study examines the usefulness of PE in different indications as a diagnostic and/or therapeutic tool when small bowel disease is suspected.

\section{Patients}

Fourteen patients underwent PE procedures over 24 months for diagnosis and treatment of suspected small bowel lesions; they were referred due to different indications. The procedures were carried out from January 2012 to December 2013. Clinical indications of PE were: IDA and/or occult GI bleeding (7 patients); overt GI bleeding (4) patients, and one patient for each abnormal small bowel radiology, persistent vomiting and chronic diarrhea.

\section{Inclusion criteria}

All patients were examined by both EGD and colonoscopy and revealed negative findings.

\section{Exclusion criteria}

There are no absolute contraindications to PE. Suspected or already known stenoses are, in fact, a very good indication for the push-and-pull enteroscopy, which is useful for their further diagnostic assessment. Postprocedural observation of the patients is also important for the timely detection of potential complications, particularly after endoscopic therapeutic

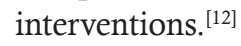

Confidentiality of data was guaranteed. Verbal witnessed consents were taken from patients for data collection. The research includes data collection only without any interference with the patient treatment.

\section{Methods}

The Pentax VSB-3440 was used for all examinations. This instrument is a video push-type enteroscope, with a total length of $2528 \mathrm{~cm}$ and a working length of $2200 \mathrm{~cm}$. The distal diameter is $11.5 \mathrm{~mm}$ and the instrument channel is $3.5 \mathrm{~mm}$. Following intubation of the pylorus and passage of the instrument to the distal duodenum, the enteroscope was advanced through the duodeno-jejunal flexure and the instrument progressing by rotation of the shaft, with shortening and straightening of the scope to facilitate advancement. Small intestinal intubation length was calculated by straightening the instrument to remove the gastric loop, and subtracting $60 \mathrm{~cm}$ from the depth inserted: $60 \mathrm{~cm}$ being the average distance from incisors to pylorus (range $40-80 \mathrm{~cm}$ ). All enteroscopic examinations were performed by author of this study.

\section{Results}

This study included 14 patients 6 males (43\%) and 8 females (57\%), their ages ranged from 17 to 67 years with a mean age 48.6 years.

Table 1 and Figure 1 show that IDA was the main indication of PE examination which represented 7/14 (50\%), while four cases presented with recurrent episodes of melena $(28.6 \%)$, and finally one case for each of abnormal computed tomography (CT) findings (dilated loops with air fluid levels), persistent vomiting and chronic diarrhea.

On the other hand, PE examination of these cases achieved diagnosis in $8 / 14$ patients (57\%) [Figure 2] with a distribution pattern as the following: Varices $3 / 8(37 \%)$, arteriovenous malformations (AVMs) 2/8 (25\%), ischemia 1/8 (12.5\%), infestations 1 (12.5\%), nonspecific inflammation $1(12.5 \%)$ [Figure 3].

Diagnosis was achieved only in 3 out of 7 patients presented with IDA while all the studied cases presented with overt bleeding were diagnosed; on the other hand, only one patient

\begin{tabular}{|c|c|c|c|c|}
\hline Age/sex & Indication & $\begin{array}{l}\text { Enteroscopic } \\
\text { findings }\end{array}$ & Therapy & Outcome \\
\hline 37/male & Melena & Jejunal varices & Surgery & Died \\
\hline 35/female & IDA & Jejunal AVMs & Medical & $\mathrm{Hb}$ stable \\
\hline 63/female & IDA & $\begin{array}{l}\text { Duodenal, jejunal } \\
\text { infestation }\end{array}$ & Medical & $\mathrm{Hb}$ stable \\
\hline $67 /$ female & Melena & $\begin{array}{l}\text { Jejunal ischemic } \\
\text { necrosis }\end{array}$ & Surgery & Died \\
\hline $17 /$ male & IDA & Jejunal varices & Surgery & Missed \\
\hline 59/female & I.O. ${ }^{*}$ CT scan & Negative & Surgery & $\mathrm{Hb}$ stable \\
\hline $55 /$ male & IDA & Negative & Medical & Recurrence \\
\hline 43/female & IDA & Negative & Medical & Recurrence \\
\hline $66 /$ female & $\begin{array}{l}\text { Persistent } \\
\text { vomiting }\end{array}$ & $\begin{array}{l}\text { Jejunal } \\
\text { inflammation }\end{array}$ & Medical & Improved \\
\hline $33 /$ male & $\begin{array}{l}\text { Chronic } \\
\text { diarrhea }\end{array}$ & Negative & Medical & Recurrence \\
\hline 52/male & IDA & Negative & Medical & Recurrence \\
\hline 49/female & IDA & Negative & Medical & Recurrence \\
\hline 57/female & Melena & Jejunal AVMs & APC & $\mathrm{Hb}$ stable \\
\hline 47/male & Melena & $\begin{array}{l}4^{\text {th }} \text { part duodenal } \\
\text { varices }\end{array}$ & Injected & Hb stable \\
\hline
\end{tabular}

$\mathrm{PE}=$ Push enteroscopy, IDA=Iron-deficiency anemia, $\mathrm{AVM}=$ Arteriovenous malformations, $\mathrm{APC}=$ Argon plasma coagulation, $\mathrm{CT}=$ Computerized tomography 


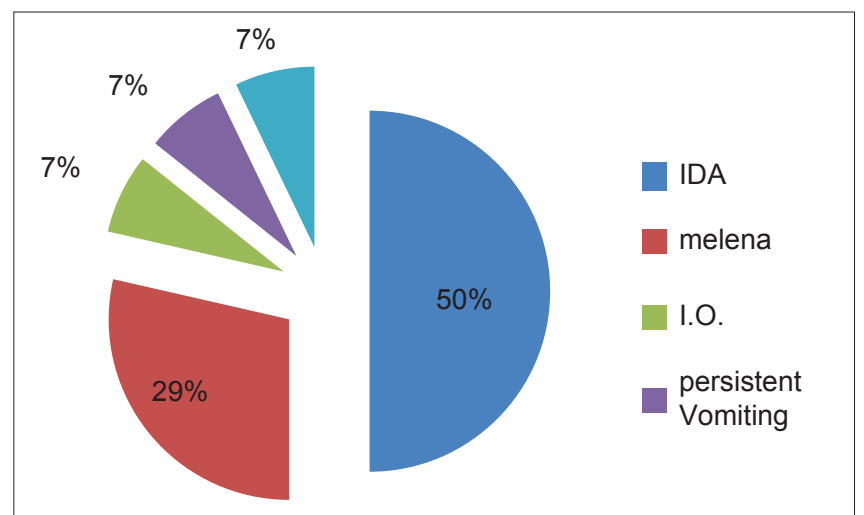

Figure 1: Indications of push enteroscope

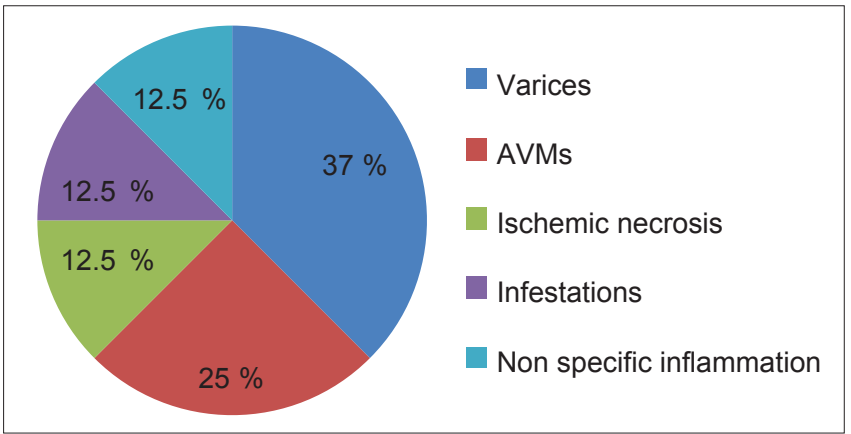

Figure 3: Distribution of the push enteroscope detected lesions among positive cases

was diagnosed from the three who presented with the other indications [Figure 4]. The mean $\mathrm{Hb}$ among the studided patients were $9.05 \mathrm{gm} / \mathrm{dl}$, however the mean prothrombin activity were $87.8 \%$ Table 2

Regarding PE therapy, two patients (14.3\%) in this study were treated by $\mathrm{PE}$, the first one had jejunal varices injected using cyanoacrylate and the other had AVMs treated by argon plasma coagulation, while medical treatment succeed to control the main indication in four cases $(28.5 \%)$. Recurrence of the symptoms was happened in five cases $(35.7 \%)$ that were normal PE examination. Finally, two cases were died after referred to surgery.

\section{Discussion}

Although PE couldn't be considered a new tool in the investigation of the small intestine as it was established during the 1980s but due to excessive loop formation, it allows only limited visualization of the small intestine; ${ }^{[11]}$ however, we established the diagnosis in 8 out of the 14 studied patients with suspected small bowel lesion [Figures 5-9], achieving diagnostic yield $57 \%$, this result is very close to Pennazio et al. $60 \%{ }^{[13]}$ on the other hand it is higher than Barkin et al. 39\% ${ }^{[14]}$ and Chen et al. 33\%. ${ }^{[15]}$

Regarding the most important indication for the PE examination among the studied patients, occult bleeding and/or IDA was the first by $7 / 14$ cases followed by overt bleeding namely melena

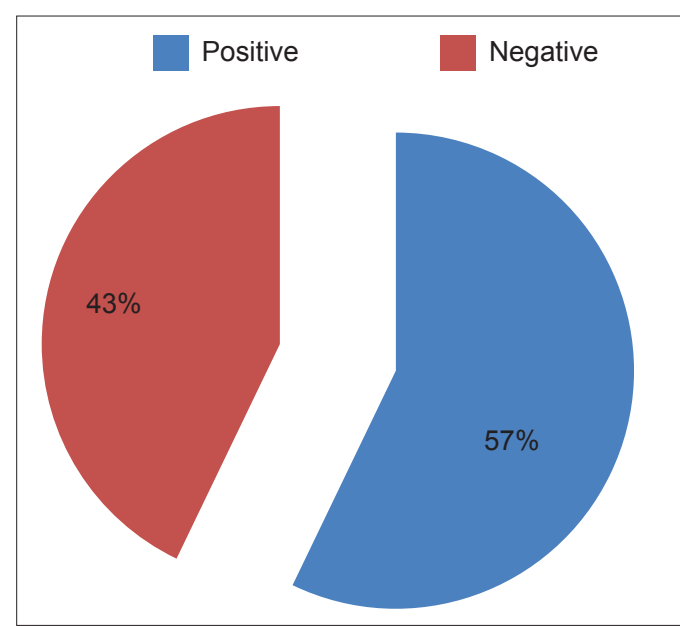

Figure 2: Push enteroscope diagnostic ability in all patients

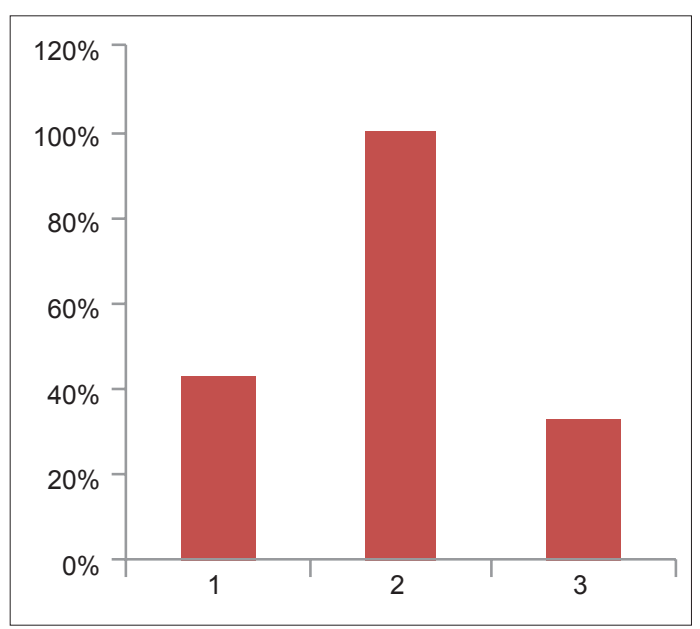

Figure 4: Comparison between achieved diagnosis in (1) occult, (2) overt bleeding and (3) other indications

by $4 / 14$ cases. Interestingly, both occult and overt bleeding were the most important indication for referring cases to be examined by PE 11/14 (78.6\%) and PE achieved diagnosis in $7 / 11$ occult and overt patients with a percent $(63.6 \%)$, this was compatible with Chak et al. $(70 \%)^{[16]}$ Chong et al. $(64 \%)^{[17]}$ and Schmit et al. $(57 \%)^{[18]}$ and in contrast to Chen et al. $47 \%{ }^{[15]}$ and Landi et al. 27\% ${ }^{[19]}$ The presence of active GI bleeding increased the diagnostic yield of the present study (4 of 4 patients). This is consistent with the published series. ${ }^{[14,20]}$ It stresses the importance of performing the procedure when patients have had evidence of active bleeding.

Since the introduction of wireless CE into clinical practice, the ability to diagnose small bowel diseases has improved greatly. ${ }^{[21]}$ However, CE is limited by the fact that biopsies cannot be taken, and interventional endoscopic procedures cannot be performed. ${ }^{[22,23]}$ Moreover, their economic costs still a burden in our country for a diagnostic tool alone.

Previous studies have revealed an overall CE "miss rate" of $10 \%$ and a miss rate of $18.6 \%$ for mass lesions especially if the lesion 


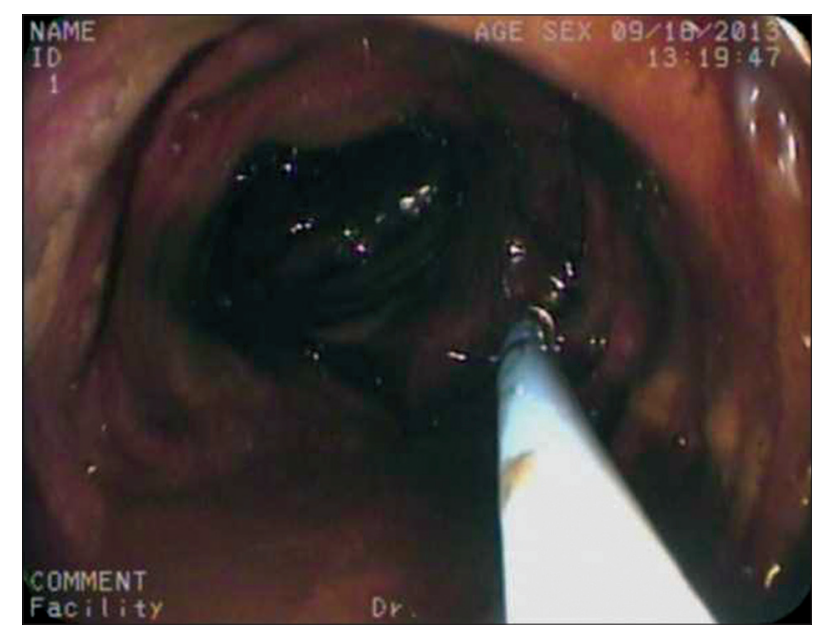

Figure 5: Ischemic necrosis of the proximal jejunum

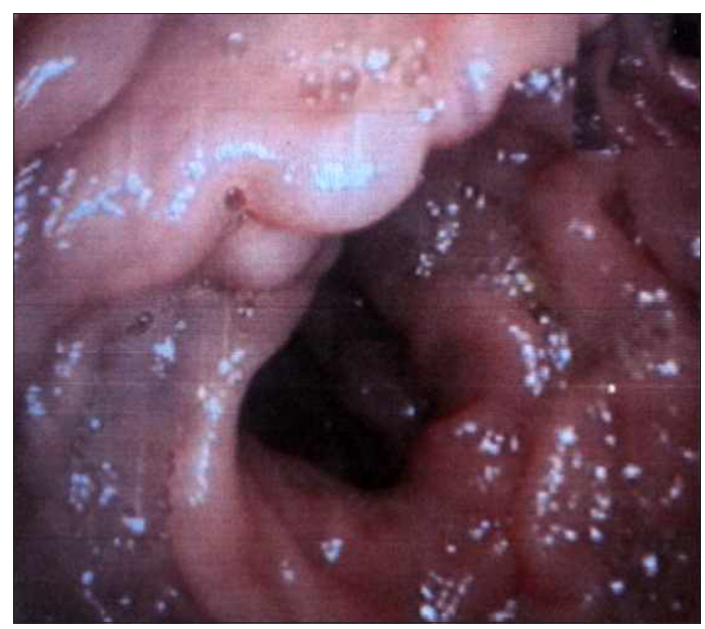

Figure 7: Jejunal varices

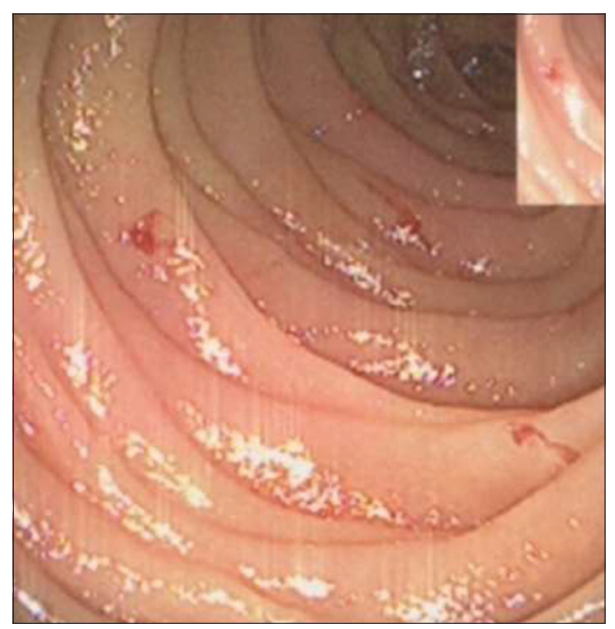

Figure 9: Multiple bleeding arteriovenous malformations in proximal jejunum

is smaller than $3 \mathrm{~cm} .{ }^{[24-26]}$ There are several possible reasons why mass lesions are missed by CE. First, unlike vascular lesions, a small bowel mass lesions are typically unifocal. At the current image capture rate of two frames per second, focal lesions are

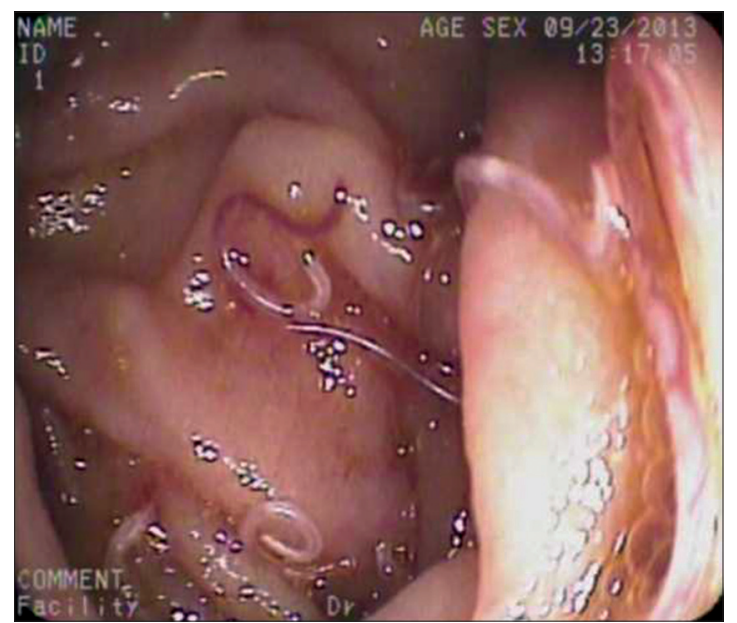

Figure 6: Heavy infestation in the proximal jejunum

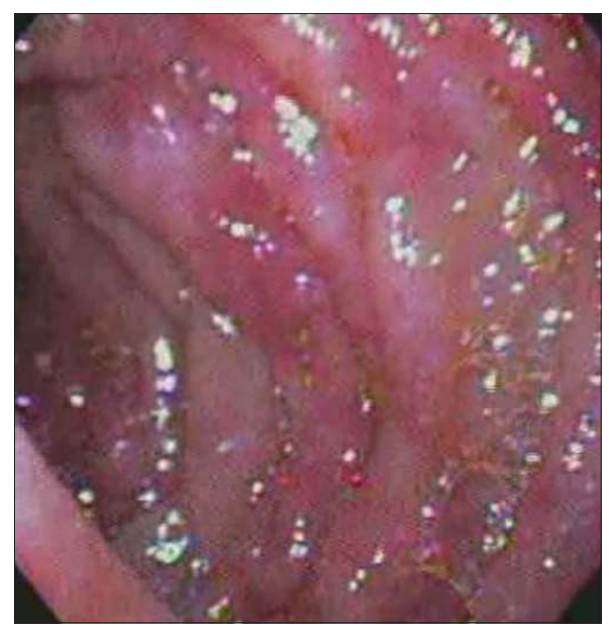

Figure 8: Nonspecific jejunitis

more likely to be missed than those that are diffuse. ${ }^{[24]}$ Second, as the capsule passes along the duodenal sweep, it may increase in speed. Therefore, mass lesions located in the proximal small bowel are more likely to be missed by CE. Lastly, incomplete small-bowel transit and blood in the lumen may obscure visualization of underlying mass lesions. ${ }^{[24,27]}$

Double balloon enteroscopy (DBE) is a novel technique, which was described in 2003. ${ }^{[21]}$ DBE has resulted in the improved diagnosis of small bowel lesions by allowing deep access into the small bowel with diagnostic and therapeutic capacity. ${ }^{[23]}$ However, DBE is actually more time-consuming than other endoscopic procedures, which typically takes about $2 \mathrm{~h}$. A longer duration often means patient intolerance and increase the risk of complications including but not limited to bowel perforation and pancreatitis. ${ }^{[21]}$ Moreover, DBE requires special endoscopic training and is not readily available in many institutions.

Push enteroscopy permits visualization and therapeutic intervention in the proximal small bowel, approximately $80-120 \mathrm{~cm}$ beyond the ligament of Treitz. ${ }^{[28,29]} \mathrm{PE}$ is safe, relatively quick and a readily available modality. However, PE 


\begin{tabular}{|c|c|c|c|}
\hline Ultrasound & $\mathrm{Hb}(\mathrm{g} / \mathrm{dl})$ & Platelets & Prothrombin activity $\%$ \\
\hline LC, splenomegaly & 9.5 & 100.000 & 74 \\
\hline Normal & 8.2 & 220.000 & 91 \\
\hline PPF & 7 & 170.000 & 100 \\
\hline Normal & 10 & 270.000 & 84 \\
\hline Normal & 7.8 & 190.000 & 87 \\
\hline Ileus, I.O. ${ }^{*} \mathrm{CT}$ & 11 & 330.000 & 90 \\
\hline Normal & 8.5 & 290.000 & 100 \\
\hline Normal & 6.9 & 310.000 & 95 \\
\hline LC & 10.9 & 160.000 & 88 \\
\hline Normal & 12 & 240.000 & 90 \\
\hline Splenomegaly & 10 & 130.000 & 77 \\
\hline Normal & 10.7 & 350.000 & 83 \\
\hline PPF & 6.5 & 190.000 & 100 \\
\hline LC, splenomegaly & 7.7 & 60.000 & 70 \\
\hline
\end{tabular}

$\mathrm{PE}=$ Push enteroscopy, CT=Computerized tomography, PPF=Periportal fibrosis, LC=Liver cirrhosis

is not a risk-free procedure. PE cannot reach the distal small intestine, and $\mathrm{PE}$ has a similar profile of complications as a conventional upper endoscopy. ${ }^{[30,31]}$

Capsule endoscopy, PE, DBE, CT scan, and magnetic resonance enterography have facilitated with the diagnosis, monitoring, and management of patients with small bowel lesions. ${ }^{[32]}$

The outcome of those patients after 3 months of follow-up was recorded. Six patients were improved clinically; however, recurrence occurred in five cases that were normal in PE examination and badly two patients died after referred to surgery.

Although this study was carried out on the referred cases over 24 months to GI endoscopy center of Tanta University Hospital, the number of those patient was relatively small (14) patients, which reflect the lack of expectancy to small intestinal lesions, however this expectancy is growing every day.

We conclude that PE has an important and useful role in this study, and it is a suitable tool to begin with it in investigations of patients whom a small bowel lesion is suspected especially in the presence of obscure overt bleeding, however, obscure occult bleeding was the most important indication among the studied patients. It is cheap, available, partially time saver and tolerable with a diagnostic yield of $57 \%$ in this study. Other endoscopic and nonendoscopic modalities will be useful in patients with $\mathrm{PE}$ negative findings especially if they are unavailable and/or high relatively expensive.

\section{References}

1. Rosenbusch G, Jansen JB, Reeders JW. Contemporary radiological examination of the small bowel. Baillieres Clin Gastroenterol 1994;8:683-700.

2. Chen RY, Taylor AC, Desmond PV. Push enteroscopy: A single centre experience and review of published series. ANZ J Surg 2002;72:215-8.

3. Pata C, Akyüz Ü, Erzın Y, Mercan A. Double-balloon enteroscopy: The diagnosis and management of small bowel diseases. Turk J Gastroenterol 2012;21:353-9.

4. Chan VO, Dermot E. Malone DE. Small Bowel Vascular Disorders. Abdominal Imaging. Berlin, Heidelberg: Springer Verlag; 2013.

5. O'Mahony S, Morris AJ, Straiton M, Murray L, MacKenzie JF. Push enteroscopy in the investigation of small-intestinal disease. QJM 1996;89:685-90.

6. Zuckerman GR, Prakash C, Askin MP, Lewis BS. American Gastroenterological Association medical position statement: Evaluation and management of occult and obscure gastrointestinal bleeding. Gastroenterology 2000;118:197-201.

7. Park DI, Ryu SH, Oh SJ, Yoo TW, Kim HJ, Cho YK, et al. Significance of endoscopy in asymptomatic premenopausal women with iron deficiency anemia. Dig Dis Sci 2006;51:2372-6.

8. Park DI, Ryu SH, Oh SJ, Yoo TW, Kim HJ, Cho YK, et al. Significance of endoscopy in asymptomatic premenopausal women with iron deficiency anemia. Dig Dis Sci 2006;51:2372-6.

9. Rai S, Hemingway D. Iron deficiency anaemia - Useful diagnostic tool for right sided colon cancers? Colorectal Dis 2005;7:588-90.

10. Pohl J, Delvaux M, Ell C, Gay G, May A, Mulder CJ, et al. European Society of Gastrointestinal Endoscopy (ESGE) Guidelines: Flexible enteroscopy for diagnosis and treatment of small-bowel diseases. Endoscopy 2008;40:609-18.

11. Sunada K, Yamamoto H, Kita H, Yano T, Sato H, Hayashi Y, et al. Clinical outcomes of enteroscopy using the double-balloon method for strictures of the small intestine. World J Gastroenterol 2005;11:1087-9.

12. Ell C, May A, Nachbar L, C Ell. A May, L Nachbar, N Plum Small bowel endoscopy: Innovations in diagnosis and treatment. Dtsch Arztebl 2006;103:A3033-9.

13. Pennazio M, Arrigoni A, Risio M, Spandre M, Rossini FP. Clinical evaluation of push-type enteroscopy. Endoscopy 1995;27:164-70.

14. Barkin JS, Ross BS. Medical therapy for chronic gastrointestinal bleeding of obscure origin. Am J Gastroenterol 1998;93:1250-4.

15. Chen RY, Taylor AC, Desmond PV. Push enteroscopy: A single centre experience and review of published series. ANZ J Surg 2002;72:215-8.

16. Chak A, Koehler MK, Sundaram SN, Cooper GS, Canto MI, Sivak MV Jr. Diagnostic and therapeutic impact of push enteroscopy: Analysis of factors associated with positive findings. Gastrointest Endosc 1998;47:18-22.

17. Chong J, Tagle M, Barkin JS, Reiner DK. Small bowel push-type fiberoptic enteroscopy for patients with occult gastrointestinal bleeding or suspected small bowel pathology. Am J Gastroenterol 1994;89:2143-6.

18. Schmit A, Gay F, Adler M, Cremer M, Van Gossum A. Diagnostic efficacy of push-enteroscopy and long-term follow-up of patients with small bowel angiodysplasias. Dig Dis Sci 1996;41:2348-52.

19. Landi B, Tkoub M, Gaudric M, Guimbaud R, Cervoni JP, Chaussade S, et al. Diagnostic yield of push-type enteroscopy in relation to indication. Gut 1998;42:421-5.

20. Cellier C, Tkoub M, Gaudric M, Guimbaud R, Auroux J, Chaussade S, et al. Comparison of push-type endoscopy and barium transit study of the small intestine in digestive bleeding and unexplained iron-deficiency anemia. Gastroenterol Clin Biol 1998;22:491-4.

21. Kaffes AJ, Koo JH, Meredith C. Double-balloon enteroscopy in the diagnosis and the management of small-bowel diseases: An initial experience in 40 patients. Gastrointest Endosc 2006;63:81-6.

22. Pata C, Akyüz Ü, Erzın Y, Mercan A. Double-balloon enteroscopy: The diagnosis and management of small bowel diseases. Turk J Gastroenterol 2012;21:353-9.

23. Ross A, Mehdizadeh S, Tokar J, Leighton JA, Kamal A, Chen A, et al. Double balloon enteroscopy detects small bowel mass lesions missed by capsule endoscopy. Dig Dis Sci 2008;53:2140-3.

24. Pata C, Akyüz Ü, Erzın Y, Mercan A. Double-balloon enteroscopy: The diagnosis and management of small bowel diseases. Turk J Gastroenterol 2012;21:353-9. 
25. Lewis BS, Eisen GM, Friedman S. A pooled analysis to evaluate results of capsule endoscopy trials. Endoscopy 2005;37:960-5.

26. Postgate A, Despott E, Burling D, Gupta A, Phillips R, O’Beirne J, et al. Significant small-bowel lesions detected by alternative diagnostic modalities after negative capsule endoscopy. Gastrointest Endosc 2008;68:1209-14.

27. Postgate A, Despott E, Burling D, Gupta A, Phillips R, O’Beirne J, et al. Significant small-bowel lesions detected by alternative diagnostic modalities after negative capsule endoscopy. Gastrointest Endosc 2008;68:1209-14.

28. Semrad CE. Small bowel enteroscopy: Territory conquered, future horizons. Curr Opin Gastroenterol 2009;25:110-5.

29. Kaffes AJ, Koo JH, Meredith C. Double-balloon enteroscopy in the diagnosis and the management of small-bowel diseases: An initial experience in 40 patients. Gastrointest Endosc 2006;63:81-6.
30. Semrad CE. Small bowel enteroscopy: Territory conquered, future horizons. Curr Opin Gastroenterol 2009;25:110-5.

31. Mylonaki M, Fritscher-Ravens A, Swain P. Wireless capsule endoscopy: A comparison with push enteroscopy in patients with gastroscopy and colonoscopy negative gastrointestinal bleeding. Gut 2003;52:1122-6.

32. Tennyson CA, Semrad CE. Advances in small bowel imaging. Curr Gastroenterol Rep 2011;13:408-17.

How to cite this article: Tawfik MA, El-Sawy AA. Push enteroscopy in management of suspected small bowel diseases: Is it still needed?. J Dig Endosc 2014;5:95-100.

Source of Support: Nil, Conflict of Interest: None declared. 